\title{
Development of Intumescent Flame Retardant for Polypropylene: Bio-epoxy Resin Microencapsulated Ammonium-polyphosphate
}

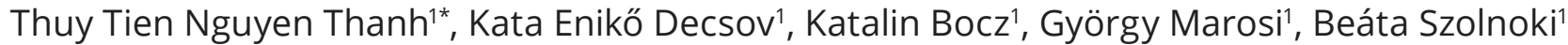 \\ 1 Department of Organic Chemistry and Technology, Faculty of Chemical Technology and Biotechnology, Budapest University of \\ Technology and Economics, H-1111, Budapest, Műegyetem rakpart 3., Hungary \\ * Corresponding author, e-mail: thuytien.nguyenthanh@edu.bme.hu
}

Received: 30 October 2021, Accepted: 21 December 2021, Published online: 26 January 2022

\begin{abstract}
As polypropylene (PP) has no charring ability on its own due to the lack of hydroxyl functional groups, the flame retardant system needs the addition of carbonizing agent in a relatively great amount. Ammonium-polyphosphate (APP), a conventional flame retardant additive was modified by microencapsulation with a sorbitol-based bioepoxy resin shell to create an intumescent flame retardant system with enhanced charring ability for PP. The flame retardant efficiency of the microencapsulated additive, which contains all the components needed in an effective intumescent flame retardant system, was evaluated in PP matrix at different loadings.

When compared to the physical mixture of the component, the microencapsuated form of APP (MCAPP) was found to have improved flame retardant efficiency in PP. The LOI values of the MCAPP containing PP samples increased by 8-11 V/V\% besides achieved V-0 classification according to the UL94 test. During cone calorimeter tests, the burning intensity was reduced (peak of heat release rate decreased by $20-35 \%$ and shifted in time), increased amount of charred residue was obtained, and based on the calculated Flame Retardancy Index (FRI) "Excellent" fire performance was achieved when MCAPP was used. The improved flame retardant performance is attributed to the effective interaction between the APP core and the readily available carbonizing shell, which promoted the formation of increased amount of char accompanied with improved heat protecting and barrier efficiency.
\end{abstract}

Keywords

polypropylene, ammonium-polyphosphate, microencapsulation, intumescent flame retardant

\section{Introduction}

Polypropylene (PP) is a widely used polymer in our daily life due to its excellent chemical resistance and mechanical properties, combined with the fact that it can be processed through many converting methods $[1,2]$. However, among the thermoplastic polymers, it has one of the highest burning heats. Even though its self-ignition temperature is relatively high $\left(570{ }^{\circ} \mathrm{C}\right)$, during its relatively smokefree combustion the polypropylene burns rapidly and completely due to its aliphatic chemical structure [3]. The high flammability of the polymer requires adequate flame retardancy which is an active research subject.

In the literature, the burning behavior of polypropylene was obtained through several burning tests. In its combustion water, formaldehyde, acetaldehyde, acetone, methanol, hydrogen, hydrogen-peroxide, carbon-monoxide, and carbon dioxide are formed [4]. Under flash pyrolysis at $520^{\circ} \mathrm{C}$, the breaking of chains was observed, and the hydrogen content of the formed gaseous products was tested. They concluded that the flammability of PP highly depends on the amount of volatile unsaturated gases, as these "fuellike" compounds can further enhance the spread of flames. The less volatile compounds act as a secondary fuel source for burning $[5,6]$. In the cool flame combustion test at $350{ }^{\circ} \mathrm{C}$ toxic gases formed as the result of the imperfect burning of polypropylene [7].

Additive flame retardants are most commonly used to reduce flammability as their manufacture is easy and relatively low cost. Currently, the most effective commercial flame retardants are halogen-containing compounds, however, their application is harmful to human health and the environment. Several researches examined the flame retardant properties of either phosphorous, nitrogen, carbon, or mineral based compounds, metal oxides, and hydroxides $[8,9]$. The combination of flame retardants shows 
better improvements in the flammability of PP over the use of each one separately [8], and so applying intumescent flame retardants to decrease the high flammability of polypropylene by reducing the amount of released volatile gases and the heat emitted during combustion could be a promising solution [9].

The main advantage of an intumescent flame retardant (IFR) system with three (char inducing blowing and charring) functions, is that the developed charred layer on the polymer surface not only acts as a heat and gas barrier, but it also effectively improves the anti-dripping effect of the polymers that overall would prevent the flames from overspreading [10]. Ammonium-polyphosphate (APP) is a conventionally used intumescent flame retardant, providing both the char inducing acid source and blowing agent, however, on its own, it is not adequate for polypropylene as the charring agent is missing from the system. Due to its chemical structure, polypropylene requires intumescent flame retardant systems containing a great additional amount of charring agent. This would overall greatly increase the additive content in the polymer that could deteriorate other properties.

The charring component, besides being incorporated as a separate additive, could be introduced in the form of a coating on the flame retardant. Microencapsulation is a highly used formulation technique in the pharmaceutical and food industry $[11,12]$, by which the active ingredients (core) are packaged within a distinctively different second material (shell) for the purpose of shielding it from the surrounding environment [13-15]. Intumescent flame retardant systems are often applied in polyolefins, polyamides, and polyesters [16, 17], and the microencapsulated APP flame retardant system proved to be beneficial for polypropylene [18-21].

The microencapsulation of flame retardants has various advantages [22] as it may improve the water-resistance of the active ingredients by isolating them [23, 24], also improves the compatibility between the active component and the polymer matrix $[25,26]$, prevents the formation of toxic gases [27-29], moreover, it can change the appearance and physical form of the flame retardant additive [30] and increase the pyrolysis temperature [13]. In the literature, ammonium-polyphosphate was encapsulated with several materials such as pentaerythritol [19], melamine-formaldehyde resin [31], cyclodextrin [32], resorcinol bis(diphenyl phosphate) [33] and bisphenol $\mathrm{A}$ epoxy resin (DGEBA) [34].
Flame retardancy index $(F R I)$ enables the comparison of different flame retardants in thermoplastic systems, based on the main features of cone calorimetry $[35,36]$. In most cases where "Good" flame retardant performance was achieved with the encapsulation of APP, the flame retardant additives were needed to be added at $30-40 \mathrm{~m} / \mathrm{m} \%$. At higher loading, still, very few have achieved the "Excellent" performance, normally due to the low charring content in the system, while the higher additive content negatively affects the mechanical properties of the composite [8]. The epoxy resin shell usually is more effective as its charring content is higher, but concerns have been raised over the use of DGEBA as its precursors are harmful to human health and the environment. Biobased epoxy resin shells from sustainable sources are in the highlight for further investigation [37-40].

Decsov et al. [22] prepared a new type of APP microcapsules through in-situ polymerization with bio-based sorbitol polyglycidyl ether-based epoxy resin, where the bioresin shell was found to be an effective charring agent, and the ideal mass ratio of the two components was found to form a complex (3 in 1) intumescent flame retardant additive. In the course of this research, our main goal was to expand the application of this all-in-one intumescent flame retardant with enhanced charring ability for polypropylene by preparing microcapsules with different bioepoxy resin shell thickness. Then the flame retardancy of the microcapsules with the optimal ratio of the components was investigated at different loading in polypropylene.

\section{Materials and methods}

\subsection{Materials}

Polypropylene Innopol CS2-9000 was provided by InnoComp Kft. (Tiszaújváros, Hungary). Exolit ${ }^{\circledR}$ AP 422type ammonium-polyphosphate received from Clariant (Muttenz, Switzerland) was applied in neat and encapsulated form as a flame retardant. Sorbitol polyglycidyl ether (SPE, epoxide equivalent weight 160-195 g/eq, ERISYS ${ }^{\circledR}$ GE-60) for bioresin shells was received from Emerald Performance Materials LLC (Vancouver, WA, USA). Ipox MH 3122 (Ipox Chemicals Kft., Budapest, Hungary) (2,2'dimethyl-4,4'-methylene bis(cyclohexylamine)), a cycloaliphatic amine-type crosslinking agent was used to cure the bio-based epoxy monomer. Absolute ethanol was purchased from Merck (Darmstadt, Germany). 


\subsection{Preparation of flame retardants}

\subsubsection{Preparation of microencapsulated APP}

Decsov et al. [22] prepared the microcapsules in 10:1, 10:2 and 10:3 mass ratio of APP to SPE in $50 \mathrm{ml}$ absolute ethanol solvent for $40 \mathrm{~g}$ APP, and they observed that with higher epoxy resin content the microcapsules tend to aggregate. In this experiment in order to include a high amount of charring agent into the flame retardant additive without the aggregation of particles during the in-situ polymerization, 10:5 mass ratio of APP to SPE microcapsules were prepared in an increased solvent amount of $150 \mathrm{ml}$ absolute ethanol for $40 \mathrm{~g}$ APP.

The microcapsules were prepared in 10:2 (APP2) and 10:5 (APP5) mass ratio of APP to SPE representing MCAPP2 and MCAPP5 microcapsules, respectively. For MCAPP2 the original solvent ratio was kept, while for MCAPP5 the increased amount was used. In absolute ethanol, the SPE bioepoxy component ( $8 \mathrm{~g}$ and $20 \mathrm{~g}$, representing 10:2 and 10:5 mass ratio of APP to SPE, respectively) and the cyclic amine type crosslinking agent $(33 \mathrm{~m} / \mathrm{m} \%$ of the SPE) were completely dispersed at room temperature and then $40 \mathrm{~g}$ neat APP was added into the solution with continuous stirring. The mixture was continuously stirred for 4 hours at reflux temperature $\left(78^{\circ} \mathrm{C}\right)$, after that, it was cooled to room temperature, filtered, washed with absolute ethanol, and dried (post-cured) at $120^{\circ} \mathrm{C}$ for 48 hours. The dried microcapsules were then powdered in a hand mortar to obtain the microencapsulated flame retardants. Table 1 shows the composition of the prepared two types of microencapsulated flame retardant additives differing in the thickness of the bioepoxy resin shell layers.

\subsubsection{Preparation of the physical mixture}

The bioepoxy component and the cyclic amine type crosslinking agent were mixed in the mass ratio of APP2 and APP5 (Table 1), representing pmAPP2 and pmAPP5 physical mixtures, then poured in the mold in a thin layer and post-cured at $120^{\circ} \mathrm{C}$ for 48 hours. The dried bioresin then was frozen in liquid nitrogen before being ground in a cryogenic grinder (IKA A 11 basic (Staufen, Germany)), then sieved through a sieve of $500 \mu \mathrm{m}$ hole size. The APP was applied in neat form without any heat pre-treatment.

Table 1 The APP2 and APP5 compositions for microcapsules (MCAPP2, MCAPP5) and physical mixtures (pmAPP2, pmAPP5)

\begin{tabular}{lccccc}
\hline \multirow{2}{*}{ Composition } & \multicolumn{2}{c}{ Ratio } & \multicolumn{3}{c}{ Mass percentage $[\mathrm{m} / \mathrm{m} \%]$} \\
& APP & SPE & APP & SPE & T58 \\
\hline APP2 & 10 & 2 & 78.95 & 15.79 & 5.26 \\
APP5 & 10 & 5 & 60.00 & 30.00 & 10.00 \\
\hline
\end{tabular}

\subsection{Preparation of flame retarded PP composites}

\subsubsection{Kneading}

The flame retarded PP samples were prepared in a Brabender Plasti-Corder Lab-Station coupled with W 50 EHT 3Z type internal mixer chamber (Brabender $\mathrm{GmbH} \& \mathrm{Co}$. KG, Duisburg, Germany). The temperature and the rotor speed were set to $180^{\circ} \mathrm{C}$ and $501 / \mathrm{min}$, respectively. The PP granules were melted first, then mixed with the flame retardant additives. The mixture was mixed for a total of $10 \mathrm{~min}$.

\subsubsection{Molding}

The kneaded materials were then hot-pressed using a Collin Teach-Line Platen Press 200E type heated press (Dr. Collin GmbH, München, Germany) within a mold of $100 \times 100 \times 4 \mathrm{~mm}^{3}$ size at $180^{\circ} \mathrm{C}$. When the material has melted in the form, it was then pressed under $20 \mathrm{kN}$ for $2 \mathrm{~min}$, then under $50 \mathrm{kN}$ for $3 \mathrm{~min}$, and finally cooled to $50{ }^{\circ} \mathrm{C}$ under $50 \mathrm{kN}$. The specimens if needed were cut into the required shapes with a table saw.

\subsection{Characterization methods}

\subsubsection{Fourier Transform Infrared Spectroscopy}

Infrared spectra (4000-400 1/cm) of the microcapsules were recorded using a Bruker Tensor 37 type Fourier transform infrared (FTIR) spectrometer (Bruker Corporation, Billerica, MA, USA) equipped with deuterated triglycine sulfate (DTGS) detector with a resolution of $41 / \mathrm{cm}$. Before testing, the powder of the microcapsules was mixed with potassium bromide (KBr) powder and cold-pressed into a suitable disk for FTIR measurement.

\subsubsection{Scanning Electron Microscopy (SEM)}

Scanning electron microscopic (SEM) micrographs of the microcapsules were taken using a JEOL JSM-5500 LV type apparatus (JEOL Ltd., Akishima, Tokyo, Japan) at an accelerating voltage of $10 \mathrm{keV}$. Before the examination, all the samples were sputter-coated with a conductive gold layer to prevent charge build-up on the surface.

\subsubsection{Thermogravimetric Analysis (TGA)}

Thermogravimetric analysis (TGA) measurements were carried out using a TA Instruments Q5000 Apparatus (TA Instruments LLC, New Castle, NH, USA) under $25 \mathrm{~mL} / \mathrm{min}$ nitrogen gas and air flow. Samples of about $10 \mathrm{mg}$ were positioned in open platinum pans. The polymer samples were heated from $25{ }^{\circ} \mathrm{C}$ to $600{ }^{\circ} \mathrm{C}$ with a $10{ }^{\circ} \mathrm{C} / \mathrm{min}$ rate (The precision on the temperature measurements is $\pm 1.5^{\circ} \mathrm{C}$ in the temperature range of $25-800{ }^{\circ} \mathrm{C}$ ). 


\subsubsection{Limiting Oxygen Index (LOI)}

Limiting oxygen index (LOI) was determined on specimens with $100 \times 10 \times 4 \mathrm{~mm}^{3}$ dimensions according to MSZ EN ISO 4589 (2000) standard using an apparatus made by FTT.

\subsubsection{UL94}

Standard UL94 flammability tests were performed according to ISO 9772 and ISO 9773.

\subsubsection{Water-resistance test}

3 samples of $100 \times 10 \times 4 \mathrm{~mm}^{3}$ dimensions from the reference and each composite were soaked in distilled water for 24 hours at $50{ }^{\circ} \mathrm{C}$. After the soaking, the samples were dried for $\sim 24$ hours at $60{ }^{\circ} \mathrm{C}$. The mass of the dry samples was measured before and after the water soaking.

\subsubsection{Mass Loss Calorimetry (MLC)}

Mass loss type cone calorimeter tests were carried out by an instrument delivered by Fire Testing Technology Ltd., (East Grinstead, West Sussex, UK), using the ISO 13927 standard method. Specimens $\left(100 \times 100 \times 4 \mathrm{~mm}^{3}\right)$ were exposed to a constant heat flux of $50 \mathrm{~kW} / \mathrm{m}^{2}$. The ignition was provided by a spark plug located $13 \mathrm{~mm}$ above the sample. The main characteristic of fire properties, including heat release rate $(H R R)$ as a function of time, time to ignition $(T T I)$, and total heat release $(T H R)$ were determined. For calculation of flame retardant index [35] $p H R R 1$ values were taken into consideration.

$F R I=\frac{\left[T H R \times \frac{p H R R 1}{T T I}\right]_{\text {Neat Polymer }}}{\left[T H R \times \frac{p H R R 1}{T T I}\right]_{\text {Composite }}}$

\subsubsection{Tensile test}

Comparative tensile tests were performed on rectangular specimens of $100 \times 10 \times 4 \mathrm{~mm}^{3}$ (width $\times$ length $\times$ depth) (the gauge length was $60 \mathrm{~mm}$ ) using a Zwick Z020 universal testing machine (Zwick GmbH \& Co. KG, Ulm, Germany) with a crosshead speed of $5 \mathrm{~mm} / \mathrm{min}$. $5 \mathrm{spec}-$ imens were tested from each composite sample. Based on the measured geometric data and the resulting stressstrain curves, the tensile strength $\left(\sigma_{M}\right)$ and the relative elongation at maximum force were calculated for each specimen using the ISO 527-1:2012 standard.

\section{Results and discussion}

\subsection{Characterization of the microcapsules}

\subsubsection{Fourier transform infrared spectroscopic evaluation of microcapsules}

Fig. 1 shows the FTIR spectra of neat APP, SPE resin, MCAPP2 and MCAPP5 microcapsules. The spectra of microcapsules include the typical absorption peaks of neat APP, while the resin-specific bands such as 2918 1/cm $\mathrm{CH}_{2}$-stretching, $14601 / \mathrm{cm} \mathrm{CH}_{2}$ bending, $11261 / \mathrm{cm} \mathrm{C}-\mathrm{O}$ ether bond, and $7461 / \mathrm{cm}$ presumably attributed to $\mathrm{CH}_{2}$ rockings are also detectable, most intensively in the spectrum of the MCAPP5, the microcapsule with the thickest bioepoxy shell. The FTIR absorbance spectra taken from the microcapsules confirmed that the bioresin was present on the surface of the filtered and dried solid APP particles after encapsulation

\subsubsection{Thermogravimetric analysis of microcapsules}

As seen in Fig. 2, the weight loss until $200{ }^{\circ} \mathrm{C}$ is negligible. Both types of microcapsules started to decompose much earlier than the highlighted area which marks the thermal decomposition temperature range for polypropylene. The MCAPP5 microcapsules have a lower degradation temperature than the MCAPP2 microcapsules and that could be beneficial regarding the protective charred layer formation in the flame retardancy of polypropylene.

When examining the theoretical degradation curves with the measured curves [22] it was observed that with

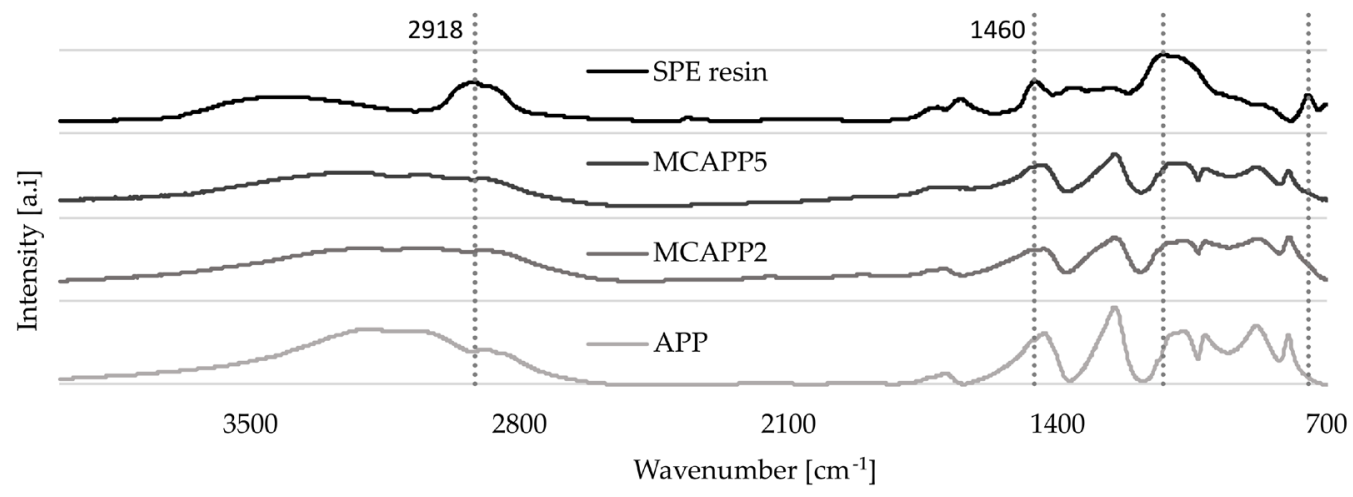

Fig. 1 FTIR absorbance spectra of the microcapsules and components 


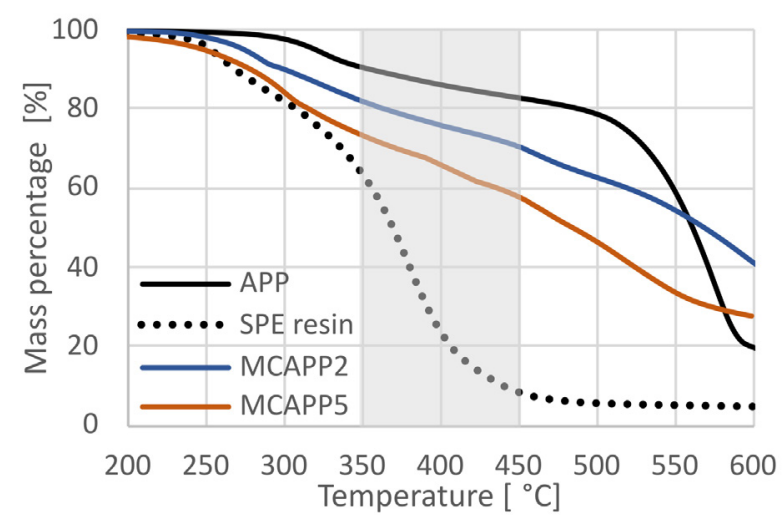

Fig. 2 Thermogravimetric analysis of the neat APP, SPE bioepoxy resin, and the microcapsules as measured under $\mathrm{N}_{2}$ atmosphere with the heating ramp of $10^{\circ} \mathrm{C} / \mathrm{min}$

the increasing amount of resin the extent of the degradation was greater at a given temperature than it was expected. This aspect is attributed to the interaction between APP and the bioresin, so with higher bioresin shell thickness the degradation temperature shifts lower for the flame retardant.

\subsubsection{Scanning electron microscopic analysis of microcapsules}

In the microscopic images shown in Fig. 3, it can be observed that the MCAPP2 microcapsules have a smoother and more spheroidal surface compared to the neat APP particles. The MCAPP5 microcapsules have a blocky structure, similar to the neat APP, but with a rough surface of the bioresin shell. Since the increased solvent amount was used during the microencapsulation, the MCAPP5 particles did not aggregate, while in the case of MCAPP2 where the original solvent ratio was kept, the smaller particles stuck onto the larger ones and formed aggregation which may cause them to disperse less in the polymer matrix. The MCAPP5 microcapsules compared to the neat APP particles, are also larger, which is attributed to the thicker shell, fully covering the particles.

\subsection{Characterization of flame retarded composites \\ 3.2.1 LOI and UL94 test results of flame retarded composites}

Different amounts of the microcapsules were loaded in PP and their flammability was tested in UL94 and LOI testing. The results, listed in Table 2, show that the microcapsules under 15\% loading achieved HB classification in UL94, while the higher loading of $20 \%$ and $25 \%$ were not able to suppress the flaming dripping in the vertical burning test. As evidence of the increased charring
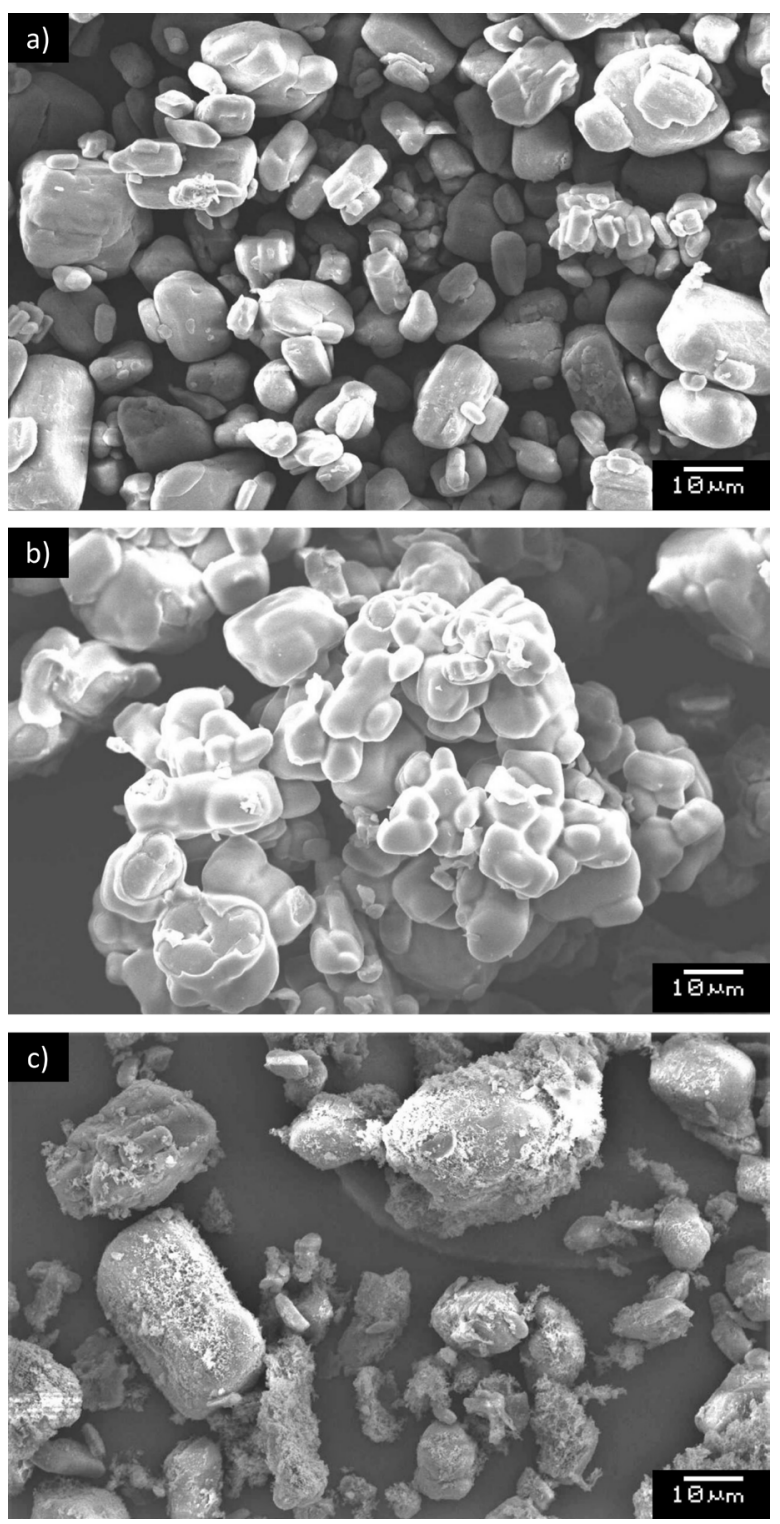

Fig. 3 Scanning electron microscopic images of microcapsules of different compositions with $1000 \times$ magnification: a) neat APP particles, b) MCAPP2 and c) MCAPP5 microcapsules

effect of the thicker resin shell on MCAPP5 microcapsules, the samples already reached V-0 classification at $30 \mathrm{~m} / \mathrm{m} \%$ FR content, while the microcapsules MCAPP2 with thinner resin shell achieved it only at higher loading of $35 \mathrm{~m} / \mathrm{m} \%$. The LOI values were, however practically the same for both microcapsules at the same loading. It is assumed that the higher content of the charring agent forms a char layer of improved barrier efficiency on the polymer which could successfully prevent the flame from dripping as a stronger and more durable structure is formed. Based on the results, only the composites with $30 \mathrm{~m} / \mathrm{m} \%$ and $35 \mathrm{~m} / \mathrm{m} \%$ flame retardant contents were selected for further investigation. 
Table 2 The results of UL94 and LOI test on the PP reference, the MCAPP2 and the MCAPP5 incorporated PP composites at different loadings

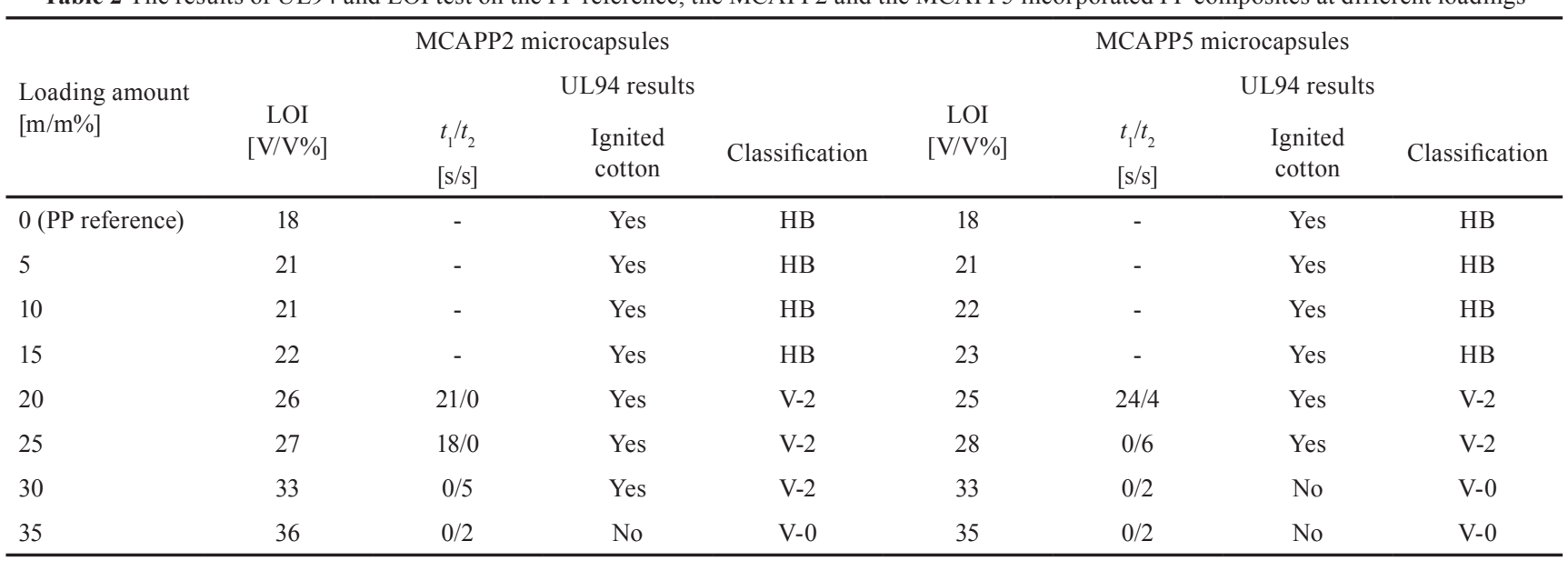

In order to prove the positive effect of the microencapsulation, the microcapsules containing samples were compared with the ones containing the physical mixture of the neat APP and ground bioepoxy resin, with the same chemical composition (Table 3 ).

When observing the effect of microencapsulation, the samples containing the physical mixture achieved significantly lower LOI values respectively, decreased by 8-11 V/V\%, but in the UL94 testing, both the microcapsules and the physical mixtures incorporated samples reached the same classification.

\subsubsection{Water-resistance test}

The mass loss of the flame retarded composites loaded at $30 \mathrm{~m} / \mathrm{m} \%$ and the reference sample is shown in Fig. 4. All samples lost some weight during the soaking process, likely due to the dissolution of APP. The physical mixture containing samples lost the most mass, 3 times more than the neat PP reference samples. While in the case of the microencapsulated flame retardants, the mass loss is noticeably lower. The sample containing MCAPP5 with the thicker resin shells showed the lowest mass loss among the flame retarded composites. The microencapsulation with bioepoxy shell almost halved the mass loss, effectively improved the water-resistance of APP and so did the water durability of the flame retarded composites.

Table 3 Comparing the results of UL94 and LOI tests on the microcapsules and physical mixtures containing PP composites

\begin{tabular}{lcccc}
\hline \multirow{2}{*}{ Sample } & \multicolumn{2}{c}{ LOI [V/V\%] } & \multicolumn{2}{c}{ UL94 } \\
& MC & pm & MC & pm \\
\hline PP+ APP2 30\% & 33 & 24 & V-2 & V-2 \\
PP+ APP2 35\% & 36 & 25 & V-0 & V-0 \\
PP+ APP5 30\% & 33 & 26 & V-0 & V-0 \\
PP+ APP5 35\% & 35 & 27 & V-0 & V-0 \\
\hline
\end{tabular}

The samples were then subject to the LOI test, where no change in the flammability was observed. The LOI values for the hot bath treated flame retarded samples remained the same as the untreated composites. The extent of the mass loss under these conditions didn't significantly affect the flame retardant properties of the PP composites.

\subsubsection{Thermogravimetric analysis of flame retarded composites}

Fig. 5 contains the thermogravimetric curves which show that the neat PP sample degraded in one step at the temperature of $315.2^{\circ} \mathrm{C}$ and left an insignificant amount of residue $(1.3 \%)$. In contrast, the flame retarded composites are degraded in several steps. The first and second ones are attributed to the degradation of $\mathrm{PP}$ and the flame retardants within the range of $300-400{ }^{\circ} \mathrm{C}$. In this temperature zone APP decomposes into polyphosphoric acid and releases ammonia, where the previous one promotes char formation with the bioresin, while the latter one acts as the blowing agent in the system.

As seen in Table 4, both the physical mixture and microcapsules containing composites showed higher

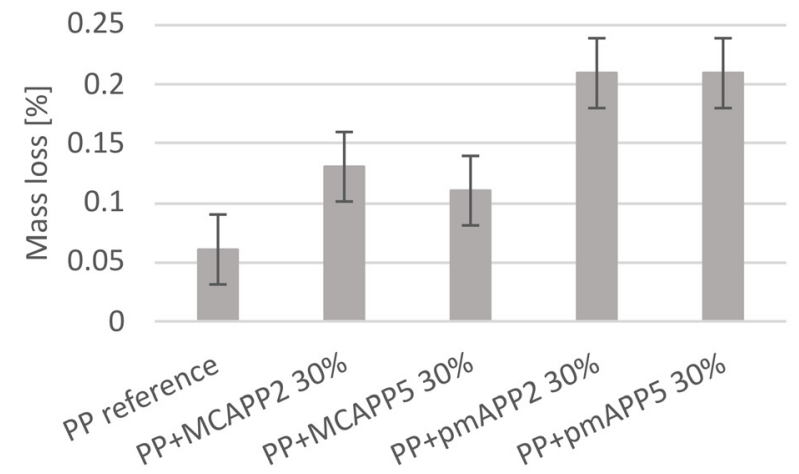

Fig. 4 The average mass loss of the reference and flame retarded samples after the hot bath test $\left(50^{\circ} \mathrm{C}, 24\right.$ hours) 


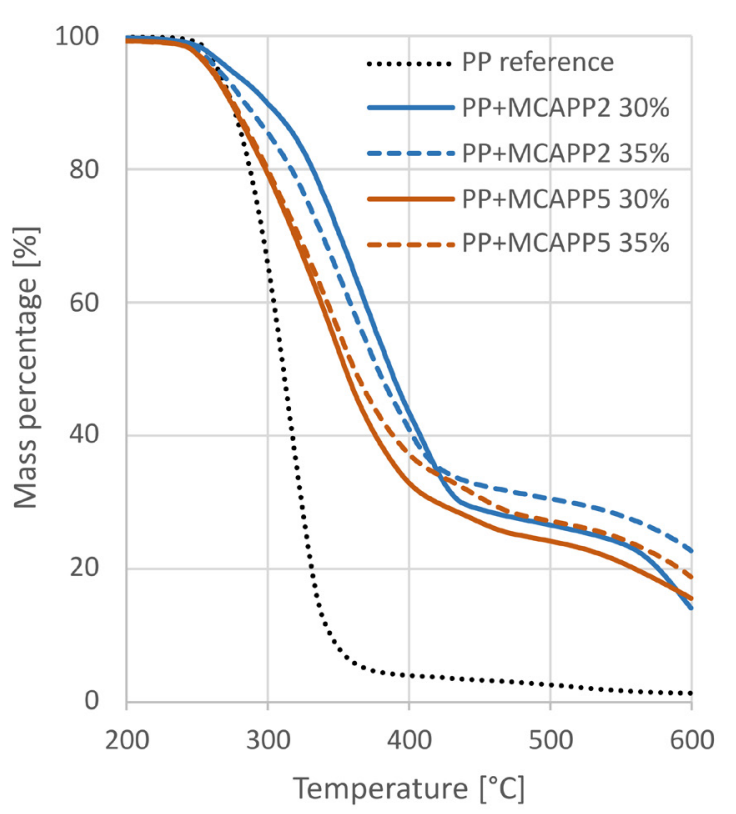

(a)

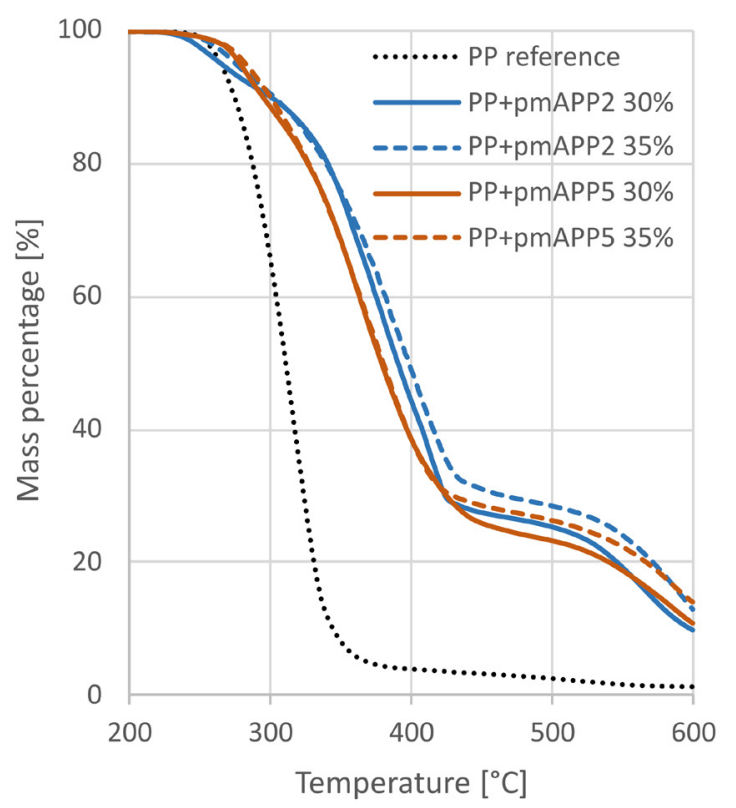

(b)

Fig. 5 The thermogravimetric curves of a) the neat polypropylene and the microcapsules flame retarded PP composites; b) the neat polypropylene and the physical mixtures flame retarded PP composites as measured under air atmosphere with the heating ramp of $10^{\circ} \mathrm{C} / \mathrm{min}$ thermal stability than the neat PP as the decomposition temperature is increased by $30-70{ }^{\circ} \mathrm{C}$. When comparing the maximum rate of weight loss of the composite, the physical mixture containing ones have a greater decomposition rate, however, their temperature at the maximum decomposition rate is $10-30{ }^{\circ} \mathrm{C}$ higher than that of the microencapsulated ones.

Even though the microcapsules containing composites showed lower thermal stability, this early degradation at slower rate resulted in higher residual mass respectively. It is assumed that in microcapsule form APP and the bioresin can readily interact with each other thus promoting the charred residue formation with the bioresin more effectively, while the physical mixture offers a smaller interface due to the physical distance between the substances. This interaction resulted in a shift of degradation to lower temperature ranges as observed in the thermal analysis of the neat components and the microcapsules. Besides, it is also indicated by the overlapping of the first and second degradation steps as its more dominant in the case of microcapsules than the physical mixtures.

The third and last step could be assigned to the degradation of the formed char residue above $500{ }^{\circ} \mathrm{C}$. The rate of degradation is higher in the case of the composites with physical mixtures, indicating lower thermal stability of the corresponding residue.

\subsubsection{Mass loss calorimetry (MLC) results of flame retarded composites}

In mass loss calorimeter tests, neat polypropylene had a short burning time (419 s) and a relatively high peak heat release rate $\left(871 \mathrm{~kW} / \mathrm{m}^{2}\right)$ during combustion (Table 5). In Fig. 6 the curves of the flame retarded samples are distinctly flatter, prolonged in time, and have a much lower peak in heat emission. After reaching the "first" heat release peak ( $p H R R 1)$, the curves decrease steadily and then suddenly jump to a "second" maximum heat emission value ( $p H R R 2)$, except for PP+pmAPP2 30\%, which is usually smaller than the first one.

Table 4 TGA data of the PP reference, the microcapsules containing, and the physical mixtures incorporated samples as measured under air atmosphere with the heating ramp of $10^{\circ} \mathrm{C} / \mathrm{min}$

\begin{tabular}{|c|c|c|c|c|c|c|c|c|c|c|}
\hline \multirow{2}{*}{ Sample } & \multicolumn{2}{|c|}{$\mathrm{T}-5 \%\left[{ }^{\circ} \mathrm{C}\right]$} & \multicolumn{2}{|c|}{$\mathrm{T}-50 \%\left[{ }^{\circ} \mathrm{C}\right]$} & \multicolumn{2}{|c|}{ dTGmax $\left[\% /{ }^{\circ} \mathrm{C}\right]$} & \multicolumn{2}{|c|}{$\mathrm{T}(\mathrm{dTGmax})\left[{ }^{\circ} \mathrm{C}\right]$} & \multicolumn{2}{|c|}{ Residue [\%] } \\
\hline & $\mathrm{MC}$ & $\mathrm{pm}$ & $\mathrm{MC}$ & $\mathrm{pm}$ & $\mathrm{MC}$ & $\mathrm{pm}$ & $\mathrm{MC}$ & $\mathrm{pm}$ & $\mathrm{MC}$ & $\mathrm{pm}$ \\
\hline PP reference & \multicolumn{2}{|c|}{264.5} & \multicolumn{2}{|c|}{310.6} & \multicolumn{2}{|c|}{1.566} & \multicolumn{2}{|c|}{315.4} & \multicolumn{2}{|c|}{1.3} \\
\hline $\mathrm{PP}+\mathrm{APP} 230 \%$ & 273.0 & 265.0 & 386.7 & 390.1 & 0.579 & 0.661 & 359.9 & 380.5 & 14.1 & 9.8 \\
\hline $\mathrm{PP}+\mathrm{APP} 235 \%$ & 264.7 & 275.2 & 373.2 & 398.3 & 0.490 & 0.627 & 352.1 & 384.2 & 21.4 & 12.9 \\
\hline $\mathrm{PP}+\mathrm{APP} 530 \%$ & 259.2 & 278.3 & 354.6 & 378.5 & 0.585 & 0.661 & 348.2 & 360.0 & 15.5 & 10.9 \\
\hline $\mathrm{PP}+\mathrm{APP} 535 \%$ & 260.5 & 282.3 & 361.0 & 379.8 & 0.540 & 0.622 & 348.7 & 382.3 & 18.7 & 14.0 \\
\hline
\end{tabular}


Table 5 Comparing the MLC data of the PP reference, the microcapsules and physical mixtures incorporated composites

\begin{tabular}{|c|c|c|c|c|c|c|c|c|c|c|c|c|c|c|}
\hline \multirow{2}{*}{ Sample } & \multicolumn{2}{|c|}{$T T I[\mathrm{~s}]$} & \multicolumn{2}{|c|}{$p H R R 1\left[\mathrm{~kW} / \mathrm{m}^{2}\right]$} & \multicolumn{2}{|c|}{$p H R R 2\left[\mathrm{~kW} / \mathrm{m}^{2}\right]$} & \multicolumn{2}{|c|}{$T H R\left[\mathrm{MJ} / \mathrm{m}^{2}\right]$} & \multicolumn{2}{|c|}{$T H R\left[\mathrm{MJ} / \mathrm{g} \mathrm{m}^{2}\right]$} & \multicolumn{2}{|c|}{$F R I[-]$} & \multicolumn{2}{|c|}{ Residue [\%] } \\
\hline & $\mathrm{MC}$ & $\mathrm{pm}$ & $\mathrm{MC}$ & $\mathrm{pm}$ & $\mathrm{MC}$ & $\mathrm{pm}$ & $\mathrm{MC}$ & $\mathrm{pm}$ & $\mathrm{MC}$ & $\mathrm{pm}$ & $\mathrm{MC}$ & $\mathrm{pm}$ & MC & pm \\
\hline PP reference & 28 & & \multicolumn{4}{|c|}{781} & \multicolumn{2}{|c|}{128} & \multicolumn{2}{|c|}{3.52} & \multicolumn{2}{|l|}{-} & \multicolumn{2}{|c|}{0} \\
\hline $\mathrm{PP}+\mathrm{APP} 230 \%$ & 21 & 33 & 156 & 192 & 138 & 267 & 98 & 94 & 2.43 & 2.33 & Good & Good & 14 & 8 \\
\hline $\mathrm{PP}+\mathrm{APP} 235 \%$ & 47 & 23 & 170 & 226 & 101 & 121 & 80 & 84 & 1.82 & 2.00 & Excellent & Good & 18 & 15 \\
\hline PP+ APP5 30\% & 45 & 29 & 134 & 176 & 88 & 135 & 90 & 89 & 2.27 & 2.22 & Excellent & Good & 10 & 11 \\
\hline $\mathrm{PP}+\mathrm{APP} 535 \%$ & 56 & 31 & 144 & 227 & 61 & 145 & 68 & 81 & 1.68 & 1.93 & Excellent & Good & 18 & 16 \\
\hline
\end{tabular}

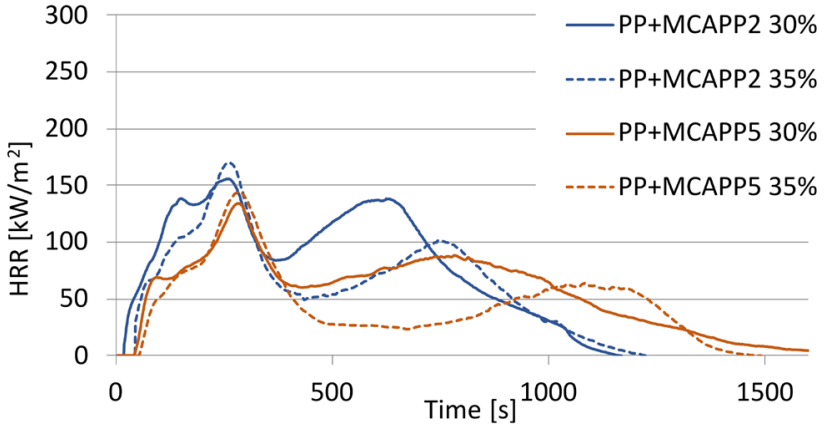

(a)

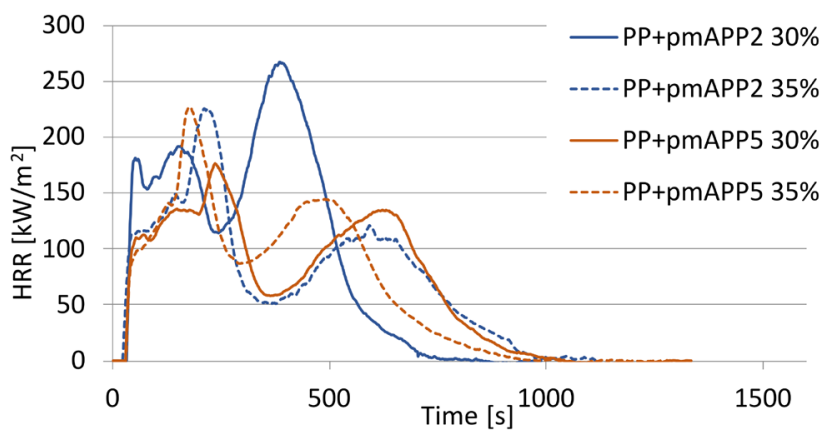

(b)

Fig. 6 The heat release curves of a) microcapsules flame retarded samples; b) physical mixtures flame retarded samples under $50 \mathrm{~kW} / \mathrm{m}^{2}$ heat flux

There is also a remarkable difference between the curves of the microcapsules containing samples: with the increase of shell thickness and additive content, the curves become flatter, and the second peak appears later and at a lower value. Examining the total heat emission, better results were obtained with both a greater shell thickness and a higher content of additives in the polymer. It can be assumed that with a larger content of carbonizing components, a thicker and better, more durable insulating layer is formed on the surface of the polymer during the combustion. This charred layer with improved heat protecting and barrier efficiency could allow a large part of the composite to burn with low intensity and prolonged in time, shielding it from the sudden heat burst and intense combustion. When the charred layer collapses that small amount of polymer that remained intact up to now is finally exposed to the heat source, resulting in the rise of heat emission, but as it is in small amount its burning is less excessive. This leads to a much lower probability of flame spreading to other components in the case of a real fire scenario.

According to the MLC result of the microencapsulated flame retardants in Table 5, the maximum heat emission values were reduced by approximately $80 \%$ compared to the PP reference sample, while a reduction of $15-40 \%$ was achieved for the total amount of heat emitted during combustion. It can be observed that the lowest maximum heat release values were achieved with the MCAPP5 microcapsules, the increase in the amount of the additive did not have a significant effect on the flammability. When comparing the physical mixture flame retarded samples, they still have a flatter and elongated curve compared to neat polypropylene, however, they burned faster with greater intensity compared to the microencapsulated flame retardant incorporated samples, their first and second peak heat release values are higher than that of the microencapsulated samples, respectively. The physical mixture incorporated samples formed a charred layer which could suppress the combustion for a short time, but when its structure weakened, most of the composite that remained intact then were suddenly exposed to the heat source, resulting in its quick and intensive burning.

The char residue of the MCAPP containing samples was higher, respectively. In the TGA, it was revealed that in the case of microcapsules the interaction of APP and the bioresin promotes char formation more effectively, yielding a char residue with higher thermal stability than the physical mixture. While in the case of the physical mixture the charring was not that efficient due to the physical distance of the flame retardant components in the matrix. This is in agreement with the behavior of the heat release curves.

Considering the flame retardancy index $(F R I)$ for the flame retarded composites, the physical mixtures and the sample PP+MCAPP2 30\% achieved "Good" grades, while the microcapsules with increasing shell thickness and additive content had "Excellent" flame retardancy performances, 
that presumably due to the microcapsule form, having lower peak heat release and reduced total heat release value. This aligns with the UL94 and LOI tests, where the composites with the "Excellent" label were also the ones that achieved the best V-0 classification and highest LOI values.

\subsubsection{Tensile test of the flame retarded composites}

The tensile strength and the elongation at yield values of the samples at the loading of $30 \mathrm{~m} / \mathrm{m} \%$ are shown in Fig. 7.

The flame retardant both in the physical mixture and microencapsulated form acts as a non-reinforcing filler in the PP matrix. The flame retardant composites have

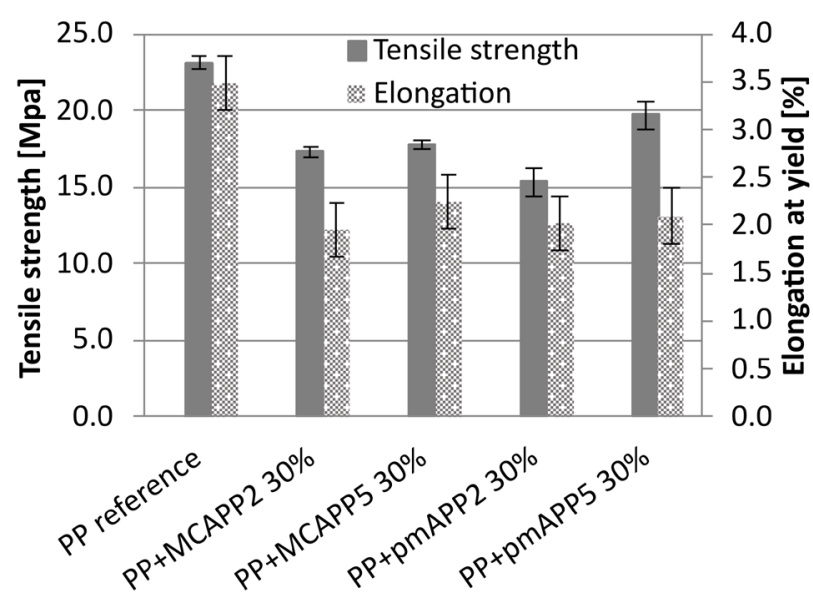

Fig. 7 Tensile strength and elongation at yield of the reference sample and flame retarded composites
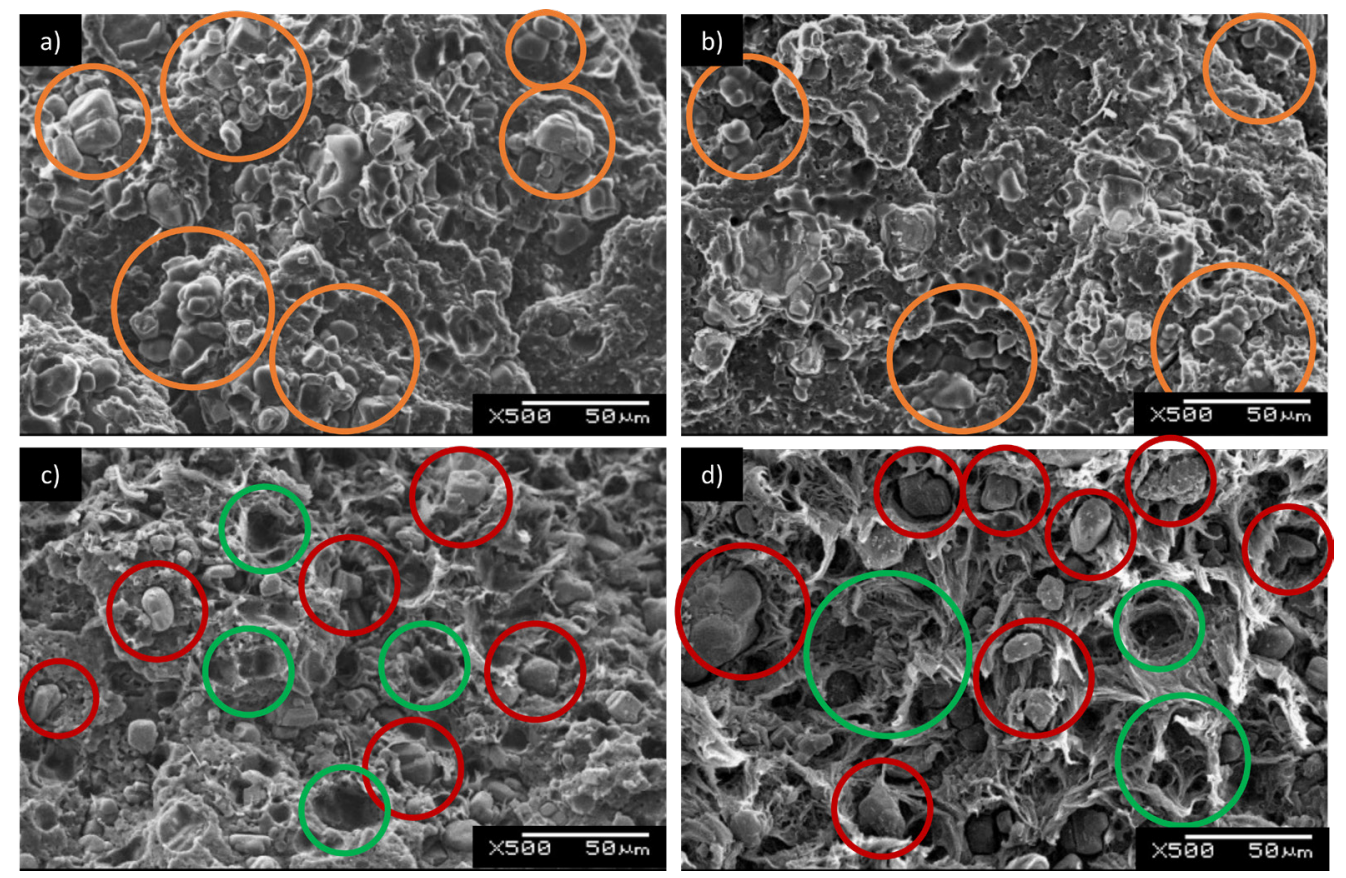

Fig. 8 SEM images of the fracture surface of flame retarded composites with 500× magnification (orange circle: aggregated microcapsules; red circle: partially detached particles; green circle: cavities): a) PP+MCAPP2 30\%, b) PP+MCAPP5 30\%, c) PP+pmAPP2 30\% and d) PP+pmAPP5 30\% a tensile strength about $25 \%$ lower than that of the neat PP reference sample, as expected due to the relatively large particle size and low aspect ratio of the flame retardant additive. The fillers reduced the deformability and so resulted in smaller elongation at yield, but no significant difference could be detected between the two forms.

\subsubsection{Scanning electron microscopic analysis of the flame retarded composites}

The microscopic images taken from the fracture surface of the samples loaded at $30 \mathrm{~m} / \mathrm{m} \%$ are shown in Fig. 8. The physical mixtures containing composites have a porous structure with a voided surface (green circle), partially detached particles on the surface and in the cavities (red circle), showing weak interfacial interaction between the neat APP and the PP matrix. The composites containing microencapsulated flame retardants in contrast have a smoother, more condensed, and less voided surface, with the microcapsules fully embedded into the polymer matrix. The microencapsulation of the APP with bioepoxy resin not only enhances the flame retardant properties of the PP but also increases the interfacial interaction between the polypropylene matrix and the flame retardant. In the SEM image of the MCAPP2 incorporated sample, the aggregated large particles (orange circle) are more visible than in the image of MCAPP5 containing composite where the microcapsules are dispersed in the polymer matrix, and only the 
small particles show some extent of aggregation. This is in agreement with the tensile results, where the MCAPP5 sample reached a somewhat higher value.

\section{Conclusion}

Polypropylene has no charring ability on its own thus noticeable amount of charring agent is needed to be added to create an effective intumescent flame retarded system that overall results in great additive content in the polymer. As a solution for that, in this study, APP particles are coated with bioepoxy resin, so that all the components of an IFR system can be introduced as one additive to PP. During the in-situ microencapsulation, increased amount of solvent was used which allowed the formation of a thicker resin shell without causing aggregation of the particles.

When compared to the physical mixture of the components, the microencapsulated form was found to have improved flame retardant efficiency. The LOI values of the bioresin encapsulated APP containing PP samples increased by $8-11 \mathrm{~V} / \mathrm{V} \%$ besides achieved $\mathrm{V}-0$ classification

\section{References}

[1] Maddah, H. A. "Polypropylene as a Promising Plastic: A Review", American Journal of Polymer Science, 6(1), pp. 1-11, 2016.

https://doi.org/10.5923/j.ajps.20160601.01

[2] Halász, I. Z., Kocsis, D., Simon, D. Á., Kohári, A., Bárány, T. "Development of Polypropylene-based Thermoplastic Elastomers with Crumb Rubber by Dynamic Vulcanization: A Potential Route for Rubber Recycling", Periodica Polytechnica Chemical Engineering, 64(2), pp. 248-254, 2020.

https://doi.org/10.3311/PPch.13962

[3] Einsele, U., Koch, W., Herlinger, H. "Investigations into the development of heat when textiles burn in air", Melliand Textilberichte, 65(3), pp. 200-206, 1984.

[4] Zhang, S., Horrocks, A. R. "A review of flame retardant polypropylene fibres", Progress in Polymer Science, 28(11), pp. 1517-1538, 2003.

https://doi.org/10.1016/j.progpolymsci.2003.09.001

[5] Jha, N. K., Misra, A. C., Bajaj, P. "Flame-Retardant Additives for Polypropylene", Journal of Macromolecular Science, Part C, 24(1), pp. 69-116, 1984.

https://doi.org/10.1080/07366578408069971

[6] Pearce, E. M., Khanna, Y. P., Raucher, D. "Thermal Analysis in Polymer Flammability", In: Turi, E. A. (ed.) Thermal Characterization of Polymeric Materials, Academic Press, London, UK, 1981, pp. 793-843.

https://doi.org/10.1016/B978-0-12-703780-6.50013-4

[7] Chaigneau, M., Le Moan, G. "Toxicity of products resulting from the cold combustion of polypropylene", Comptes Rendus des Seances de l'Academie des Sciences - Series III, 295(3), pp. 223-225, 1982. [online] Available at: http://www.ncbi.nlm.nih.gov/pubmed/6817858 [Accessed: 06 April 2020] according to the UL94 test. During cone calorimeter tests, the burning intensity was reduced ( $p H R R$ decreased by $20-35 \%$ and shifted in time), and higher residual masses (up to $18 \%$ ) were obtained, and based on the calculated FRI, "Excellent" fire performance was achieved when microencapsulated APP was used. Besides, the mechanical properties of the effectively flame retarded system remain acceptable. The improved flame retardant performance is attributed to the effective interaction between the APP core and the readily available carbonizing shell, which promotes the formation of increased amount of char accompanied with improved heat protecting and barrier efficiency.

\section{Acknowledgment}

The project was funded by the National Research, Development and Innovation Fund of Hungary in the frame of 2018-1.3.1-VKE-2018-00011 and 2019-1.3.1KK-2019-00004 projects. The research was funded by the Hungarian Scientific Research Fund, grant numbers FK128352 and KH129584.

[8] Seidi, F., Movahedifar, E., Naderi, G., Akbari, V., Ducos, F., Shamsi, R., Vahabi, H., Saeb, M. R. "Flame Retardant Polypropylenes: A Review", Polymers, 12(8), Article number: 1701, 2020.

https://doi.org/10.3390/polym12081701

[9] Zhao, W., Kumar Kundu, C., Li, Z., Li, X., Zhang, Z. "Flame retardant treatments for polypropylene: Strategies and recent advances", Composites Part A: Applied Science and Manufacturing, 145, Article number: 106382, 2021.

https://doi.org/10.1016/j.compositesa.2021.106382

[10] Camino, G., Costa, L., Martinasso, G. "Intumescent fire-retardant systems", Polymer Degradation and Stability, 23(4), pp. 359-376, 1989. https://doi.org/10.1016/0141-3910(89)90058-X

[11] Singh, M. N., Hemant, K. S. Y., Ram, M., Shivakumar, H. G. "Microencapsulation: A promising technique for controlled drug delivery", Research in Pharmaceutical Sciences, 5(2), pp. 65-77, 2010. [online] Available at: https://www.ncbi.nlm.nih.gov/pmc/ articles/PMC3093624/ [Accessed: 22 September 2021]

[12] do Amaral, P. H. R., Lopes Andrade, P., de Conto, L. C. "Microencapsulation and Its Uses in Food Science and Technology: A Review", In: Salaün, F. (ed.) Microencapsulation - Processes, Technologies and Industrial Applications, IntechOpen, London, UK, 2019, Chapter 6. https://doi.org/10.5772/intechopen.81997

[13] Abu-Thabit, N. Y., Makhlouf, A. S. H. "Recent Advances in Nanocomposite Coatings for Corrosion Protection Applications", In: Makhlouf, A. S. H., Scharnweber, D. (eds.) Handbook of Nanoceramic and Nanocomposite Coatings and Materials, Butterworth-Heinemann, Oxford, UK, 2015, pp. 515-549. https://doi.org/10.1016/B978-0-12-799947-0.00024-9 
[14] Lao, L. L., Peppas, N. A., Boey, F. Y. C., Venkatraman, S. S. "Modeling of drug release from bulk-degrading polymers", International Journal of Pharmaceutics, 418(1), pp. 28-41, 2011. https://doi.org/10.1016/j.ijpharm.2010.12.020

[15] Berkland, C., Kipper, M. J., Narasimhan, B., Kim, K., Pack, D. W. "Microsphere size, precipitation kinetics and drug distribution control drug release from biodegradable polyanhydride microspheres", Journal of Controlled Release, 94(1), pp. 129-141, 2004. https://doi.org/10.1016/j.jconrel.2003.09.011

[16] Bourbigot, S., Le Bras, M., Duquesne, S., Rochery, M. "Recent advances for intumescent polymers", Macromolecular Materials and Engineering, 289(6), pp. 499-511, 2004. https://doi.org/10.1002/mame.200400007

[17] Vandersall, H. "Intumescent coating systems, their development and chemistry", Journal of Fire \& Flammability, 1, pp. 97-140, 1970.

[18] Wu, K., Wang, Z., Hu, Y. "Microencapsulated ammonium polyphosphate with urea-melamine-formaldehyde shell: preparation, characterization, and its flame retardance in polypropylene", Polymers for Advanced Technologies, 19(8), pp. 1118-1125, 2008. https://doi.org/10.1002/pat.1095

[19] Chen, X., Jiao, C. "Study on flame retardance of co-microencapsulated ammonium polyphosphate and pentaerythritol in polypropylene", Journal of Fire Sciences, 28(6), pp. 509-521, 2010. https://doi.org/10.1177/0734904110363795

[20] Wang, Z., Liu, Y., Li, J. "Regulating Effects of Nitrogenous Bases on the Char Structure and Flame Retardancy of Polypropylene/ Intumescent Flame Retardant Composites", ACS Sustainable Chemistry and Engineering, 5(3), pp. 2375-2383, 2017. https://doi.org/10.1021/acssuschemeng.6b02712

[21] Bourbigot, S., Sarazin, J., Bensabath, T., Samyn, F., Jimenez, M. "Intumescent polypropylene: Reaction to fire and mechanistic aspects", Fire Safety Journal, 105, pp. 261-269, 2019. https://doi.org/10.1016/j.firesaf.2019.03.007

[22] Decsov, K., Bocz, K., Szolnoki, B., Bourbigot, S., Fontaine, G., Vadas, D., Marosi, G. "Development of Bioepoxy Resin Microencapsulated Ammonium-Polyphosphate for Flame Retardancy of Polylactic Acid", Molecules, 24(22), Article number: 4123, 2019. https://doi.org/10.3390/molecules24224123

[23] Ni, J., Song, L., Hu, Y., Zhang, P., Xing, W. "Preparation and characterization of microencapsulated ammonium polyphosphate with polyurethane shell by in situ polymerization and its flame retardance in polyurethane", Polymers for Advanced Technologies, 20(12), pp. 999-1005, 2009. https://doi.org/10.1002/pat.1354

[24] Zhang, Y.-K., Wu, K., Zhang, K., Wei, X.-R., Shen, M. "Influence of Microencapsulation on Combustion Behavior and Thermal Degradation of Intumescent Flame-Retarded Epoxy Composite", Polymer-Plastics Technology and Engineering, 51(10), pp. 1054-1061, 2012. https://doi.org/10.1080/03602559.2012.689054

[25] Wang, B., Sheng, H., Shi, Y., Hu, W., Hong, N., Zeng, W., Ge, H., Yu, X., Song, L., Hu, Y. "Recent advances for microencapsulation of flame retardant", Polymer Degradation and Stability, 113, pp. 96-109, 2015.

https://doi.org/10.1016/j.polymdegradstab.2015.01.008
[26] Marosi, G., Hirsch, E., Bocz, K., Toldy, A., Szolnoki, B., Bodzay, B., Csontos, I., Farkas, A., Balogh, A., Démuth, B., Nagy, Z. K., Pataki, H. "Pharmaceutical and Macromolecular Technologies in the Spirit of Industry 4.0", Periodica Polytechnica Chemical Engineering, 62(4), pp. 457-466, 2018. https://doi.org/10.3311/PPch.12870

[27] Wang, Z., Qu, B., Fan, W., Huang, P. "Combustion characteristics of halogen-free flame-retarded polyethylene containing magnesium hydroxide and some synergists", Journal of Applied Polymer Science, 81(1), pp. 206-214, 2001. https://doi.org/10.1002/app.1430

[28] Wu, Q., Lü, J., Qu, B. "Preparation and characterization of microcapsulated red phosphorus and its flame-retardant mechanism in halogen-free flame retardant polyolefins", Polymer International, 52(8), pp. 1326-1331, 2003. https://doi.org/10.1002/pi.1115

[29] Fang, S., Hu, Y., Song, L., Zhan, J., He, Q. "Mechanical properties, fire performance and thermal stability of magnesium hydroxide sulfate hydrate whiskers flame retardant silicone rubber", Journal of Materials Science, 43(3), pp. 1057-1062, 2008. https://doi.org/10.1007/s10853-007-2241-2

[30] Salaün, F., Creach, G., Rault, F., Giraud, S. "Microencapsulation of bisphenol-A bis (diphenyl phosphate) and influence of particle loading on thermal and fire properties of polypropylene and polyethylene terephtalate", Polymer Degradation and Stability, 98(12), pp. 2663-2671, 2013.

https://doi.org/10.1016/j.polymdegradstab.2013.09.030

[31] Wang, X., Hu, Y., Song, L., Xuan, S., Xing, W., Bai, Z., Lu, H. "Flame retardancy and thermal degradation of intumescent flame retardant poly(lactic acid)/starch biocomposites", Industrial and Engineering Chemistry Research, 50(2), pp. 713-720, 2011. https://doi.org/10.1021/ie1017157

[32] Wang, B., Qian, X., Shi, Y., Yu, B., Hong, N., Song, L., Hu, Y. "Cyclodextrin microencapsulated ammonium polyphosphate: Preparation and its performance on the thermal, flame retardancy and mechanical properties of ethylene vinyl acetate copolymer", Composites Part B: Engineering, 69, pp. 22-30, 2015. https://doi.org/10.1016/j.compositesb.2014.09.015

[33] Shi, X., Ju, Y., Zhang, M., Wang, X. "The intumescent flame-retardant biocomposites of poly(lactic acid) containing surface-coated ammonium polyphosphate and distiller's dried grains with solubles (DDGS)", Fire and Materials, 42(2), pp. 190-197, 2018. https://doi.org/10.1002/fam.2479

[34] Liu, L., Zhang, Y., Li, L., Wang, Z. "Microencapsulated ammonium polyphosphate with epoxy resin shell: Preparation, characterization, and application in EP system", Polymers for Advanced Technologies, 22(12), pp. 2403-2408, 2011. https://doi.org/10.1002/pat.1776

[35] Vahabi, H., Kandola, B. K., Saeb, M. R. "Flame Retardancy Index for thermoplastic composites", Polymers, 11(3), Article number: 407, 2019. https://doi.org/10.3390/polym11030407

[36] Vahabi, H., Laoutid, F., Mehrpouya, M., Saeb, M. R., Dubois, P. "Flame retardant polymer materials: An update and the future for 3D printing developments", Materials Science and Engineering: R: Reports, 144, Article number: 100604, 2021. https://doi.org/10.1016/j.mser.2020.100604 
[37] Wu, K., Zhang, Y., Hu, W., Lian, J., Hu, Y. "Influence of ammonium polyphosphate microencapsulation on flame retardancy, thermal degradation and crystal structure of polypropylene composite", Composites Science and Technology, 81, pp. 17-23, 2013. https://doi.org/10.1016/j.compscitech.2013.03.018

[38] Rad, E. R., Vahabi, H., de Anda, A. R., Saeb, M. R., Thomas, S. "Bio-epoxy resins with inherent flame retardancy", Progress in Organic Coatings, 135, pp. 608-612, 2019.

https://doi.org/10.1016/j.porgcoat.2019.05.046
[39] Movahedifar, E., Vahabi, H., Saeb, M. R., Thomas, S. "Flame Retardant Epoxy Composites on the Road of Innovation: An Analysis with Flame Retardancy Index for Future Development", Molecules, 24(21), Article number: 3964, 2019. https://doi.org/10.3390/molecules24213964

[40] Seidi, F., Jouyandeh, M., Taghizadeh, M., Taghizadeh, A., Vahabi, H., Habibzadeh, S., Formela, K., Saeb, M. R. "MetalOrganic Framework (MOF)/Epoxy Coatings: A Review", Materials, 13(12), Article number: 2881, 2020.

https://doi.org/10.3390/ma13122881 